\title{
Author Index Volume 5 (2011)
}

The issue number is given in front of the pagination

Abraham, A., see Panda, M. (4) 347-356

Akoumianakis, D., N. Vidakis, G. Vellis, D. Kotsalis, G. Milolidakis, A. Plemenos, A. Akrivos and D. Stefanakis, Transformable boundary artifacts for knowledge-based work in cross-organization virtual communities spaces (1) 65-82

Akrivos, A., see Akoumianakis, D. (1) 65-82

Anya, O., A. Nagar and H. Tawfik, Building adaptive systems for collaborative e-work: The eWorkbench approach (1) 83-100

Assal, H., see Pohl, J. (3) 201-217

Bellik, Y., see Heinroth, T. (1) 31-46

Brittain, M. and M. Ma, Simulation of autonomous crowd behaviour on Xbox 360 (3) 253-271

Brusilovsky, P., see Loboda, T.D. (1) 17-30

Call for papers, (3) 295-296

Chan, C.-K. and H.-F. Leung, Belief-based stability in non-transferable utility coalition formation with uncertainty (2) 151-162

Chattopadhyay, S., see Daneshgar, F., (2) 189-199

Ciarkowski, A., see Szwoch, G. (2) 177-188

Czyzewski, A., see Szwoch, G. (2) 177-188

Dalka, P., see Szwoch, G. (2) 177-188

Daneshgar, F. and S. Chattopadhyay, A framework for crisis management in developing countries (2) 189-199

Das, S., see Panda, M. (4) 347-356

Ghosh, S. and A. Konar, An evolutionary approach to velocity and traffic sensitive call admission control (4) 357-369

Grady, J., see Loboda, T.D. (1) 17-30

Hegedus, M.J., R.B. Paranjape and M. Mehrandezh, A new adaptive sensor fusion localization method for passive acoustic arrays (4) 333-345
Hégron, G., see Zaki, C. (4) 297-307

Heinroth, T., A. Kameas, G. Pruvost, L. Seremeti, Y. Bellik and W. Minker, Human-computer interaction in next generation ambient intelligent environments (1) 31-46

Inoko, K., H. Matsumoto and C. Kuroda, Knowledgebased environments for instructors' decision making in chemical process laboratory (1) 47-63

Kala, R., A. Shukla and R. Tiwari, Modular symbiotic adaptive neuro evolution for high dimensionality classificatory problems (4) 309-319

Kameas, A., see Heinroth, T. (1) 31-46

Knight, B., see Petridis, M. (4) 321-331

Konar, A., see Ghosh, S. (4) 357-369

Kotsalis, D., see Akoumianakis, D. (1) 65-82

Kuroda, C., see Inoko, K. (1) 47-63

Leung, H.-F., see Chan, C.-K. (2) 151-162

Loboda, T.D., P. Brusilovsky and J. Grady, An agent for versatile intelligence analysis system (1) 17-30

Ma, J., see Petridis, M. (4) 321-331

Ma, M., see Brittain, M. (3) 253-271

Matsumoto, H., see Inoko, K. (1) 47-63

Mehrandezh, M., see Hegedus, M.J. (4) 333-345

Mentzas, G., see Panagiotou, D. (2) 163-175

Milolidakis, G., see Akoumianakis, D. (1) 65-82

Minker, W., see Heinroth, T. (1) 31-46

Moreau, G., see Zaki, C. (4) 297-307

Nagar, A., see Anya, O. (1) 83-100

Ouyang, J., N. Patel and I.K. Sethi, From centralized to distributed decision tree induction using CHAID and fisher's linear discriminant function algorithms (2) 133-149 
Panagiotou, D., F. Paraskevopoulos and G. Mentzas, Knowledge-based interaction in software development (2) 163-175

Panda, M., A. Abraham, S. Das and M.R. Patra, Network intrusion detection system: A machine learning approach (4) 347-356

Papageorgiou, E.I., A Fuzzy Inference Map approach to cope with uncertainty in modeling medical knowledge and making decisions (3) 219-235

Paracha, S. and O. Yoshie, Exploring the role of drama and storyboarding in learner-centered scenario generation (3) 237-252

Paranjape, R., see Yang, Y. (2) 113-131

Paranjape, R.B., see Hegedus, M.J. (4) 333-345

Paraskevopoulos, F., see Panagiotou, D. (2) 163-175

Patel, N., see Ouyang, J. (2) 133-149

Patra, M.R., see Panda, M. (4) 347-356

Petridis, M., J. Ma and B. Knight, Temporal model for business process (4) 321-331

Plemenos, A., see Akoumianakis, D. (1) 65-82

Pohl, J., H. Assal and K.J. Pohl, Intelligent software for ecological building design (3) 201-217

Pohl, K.J., see Pohl, J. (3) 201-217

Pruvost, G., see Heinroth, T. (1) 31-46

Savvopoulos, A. and M. Virvou, User modelling server for adaptive help (1) 3-16

Seremeti, L., see Heinroth, T. (1) 31-46

Servières, M., see Zaki, C. (4) 297-307

Sethi, I.K., see Ouyang, J. (2) 133-149

Shukla, A., see Kala, R. (4) 309-319

Stathopoulou, I.-O. and G.A. Tsihrintzis, Appearance- based face detection with artificial neural networks (2) $101-111$

Stefanakis, D., see Akoumianakis, D. (1) 65-82

Szczuko, P., see Szwoch, G. (2) 177-188

Szwoch, G., P. Dalka, A. Ciarkowski, P. Szczuko and A. Czyzewski, Visual object tracking system employing fixed and PTZ cameras (2) 177-188

Taghezout, N. and P. Zaraté, An agent-based simulation approach in an IDSS for evaluating performance in flow-shop manufacturing system (3) 273-293

Tawfik, H., see Anya, O. (1) 83-100

Tiwari, R., see Kala, R. (4) 309-319

Tsihrintzis, G.A. and M. Virvou, Guest-editorial (1) 1

Tsihrintzis, G.A., see Stathopoulou, I.-O. (2) 101-111

Vellis, G., see Akoumianakis, D. (1) 65-82

Vidakis, N., see Akoumianakis, D. (1) 65-82

Virvou, M., see Savvopoulos, A. (1) 3-16

Virvou, M., see Tsihrintzis, G.A. (1) 1

Yang, Y. and R. Paranjape, A multi-agent system for course timetabling (2) 113-131

Yoshie, O., see Paracha, S. (3) 237-252

Zaki, C., E. Zekri, M. Servières, G. Moreau and G. Hégron, Generic modeling of application and spatiotemporal data: Application to the study of pedestrian behavior (4) 297-307

Zaraté, P., see Taghezout, N. (3) 273-293

Zekri, E., see Zaki, C. (4) 297-307 